Miami Nature Biotechnology Short Reports

TheScientificWorld (2001) 1 (S3), 96SR

ISSN 1532-2246; DOI 10.1100/tsw.2001.201

\title{
CRITICAL ROLE OF SMAD AND AP-1 COMPLEXES IN TGF- $\beta$-DEPENDENT APOPTOSIS
}

\author{
Yasuko Yamamura ${ }^{1,2, *}$, Xianxin Hua ${ }^{1}$, Svetlana Bergelson ${ }^{1}$, and Harvey F. Lodish ${ }^{1}$ \\ ${ }^{1}$ Whitehead Institute for Biomedical Research, Cambridge, Massachusetts 02142, USA and \\ ${ }^{2}$ Department of Retroviral Regulation, Graduate School, Tokyo Medical and Dental University, 1- \\ 5-45 Yushima, Bunkyo-ku, Tokyo 113-8519, Japan \\ *yama.mbch@med.tmd.ac.jp
}

INTRODUCTION. Transforming growth factor- $\beta 1$ (TGF- $\beta 1$ ) induces not only cell growth inhibition but also apoptosis in hepatocytes, myeloid cells, and epithelial cells. Smad complexes (Smad2-Smad4 and Smad3-Smad4) are identified as key signaling molecules which transmit TGF- $\beta 1$ signal for growth inhibition from the TGF- $\beta$ receptors to the nucleus $(1,2)$. However, their roles are unclear in the induction of apoptosis. Our results show here that both Smad and AP-1 complexes play a critical role in TGF- $\beta 1$ signaling for apoptosis.

METHOD. Apoptosis was quantified by a photometric enzyme-immunoassay measuring the presence of cytoplasmic histone-associated DNA-fragments (mono- and oligonucleosomes) as a result of apoptosis. Nuclear extracts were prepared from TGF- $\beta 1$-stimulated cells and an electrophoretic mobility shift assay was performed using a radiolabeled complementary oligonucleotides containing the consensus AP-1 binding site, TPA-responsive gene promoter element (TRE) as a probe.

RESULTS. Overexpression of a dominant-negative Smad3 mutant or inhibitory Smad7, both of which impair Smad-mediated signal transduction, inhibited TGF- $\beta 1$-dependent apoptosis. Only the AP-1 complex consisting of JunD and FosB proteins (JunD-FosB) was markedly activated during TGF- $\beta 1$-dependent apoptosis. FosB substantially enhanced Smad3-Smad4dependent transcription, and dominant-negative FosB blocked TGF- $\beta 1$-dependent apoptosis but not growth inhibition. Overexpression of JunD-FosB significantly enhanced induction of apoptosis by TGF- $\beta 1$. Moreover, JunD-FosB bound to the AP-1 binding site, TRE and recruited Smad3-Smad4 to form a multi-component complex.

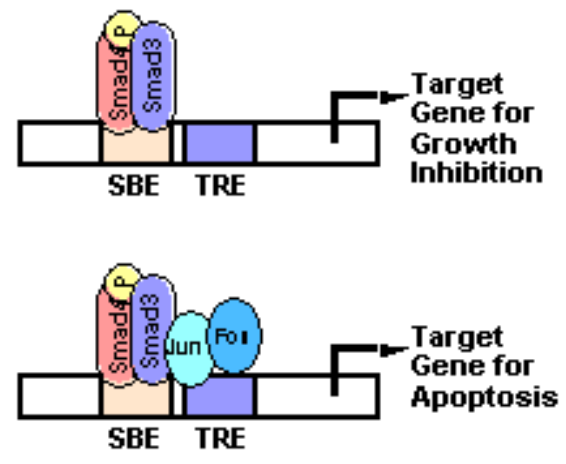


Fig. 1. Model of cooperative interaction of Smad and AP-1 complexes in TGF- $\beta 1$-dependent apoptosis.

DISCUSSION. Although Smad proteins are suggested to cooperate with the AP-1 complex to regulate transcription of target genes, involvement of the AP-1 complex has not been demonstrated in cell growth inhibition or apoptosis induced by TGF- $\beta 1$. We show here that not only Smad but also AP-1 complexes actually participate in TGF- $\beta 1$ signaling for apoptosis. Moreover, our present results suggest synergistic cooperation between Smad and AP-1 complexes in TGF- $\beta 1$-dependent apoptosis, but not growth inhibition. Smad proteins may positively or negatively modify transcription of target genes through cooperation with their DNA-binding partners to exert diverse biological activities.

ACKNOWLEDGEMENT. This work was supported by National Institutes of Health grant CA63260 (to H.F.L.) and grants-in-aid for scientific research from the Ministry of Education, Science, Sports and Culture of Japan (to Y.Y.). Y.Y. was supported by a fellowship from the Research Training Program of the National Cancer Institute of the United States of America and the Japanese Foundation for Cancer Research of Japan.

\section{REFERENCES.}

1. Heldin, C.H., Miyazono, K., and Ten Dijke, P. (1997) Nature 390, 465-471

2. Massague, J. (1998) Annu. Rev. Biochem. 67, 753-791 

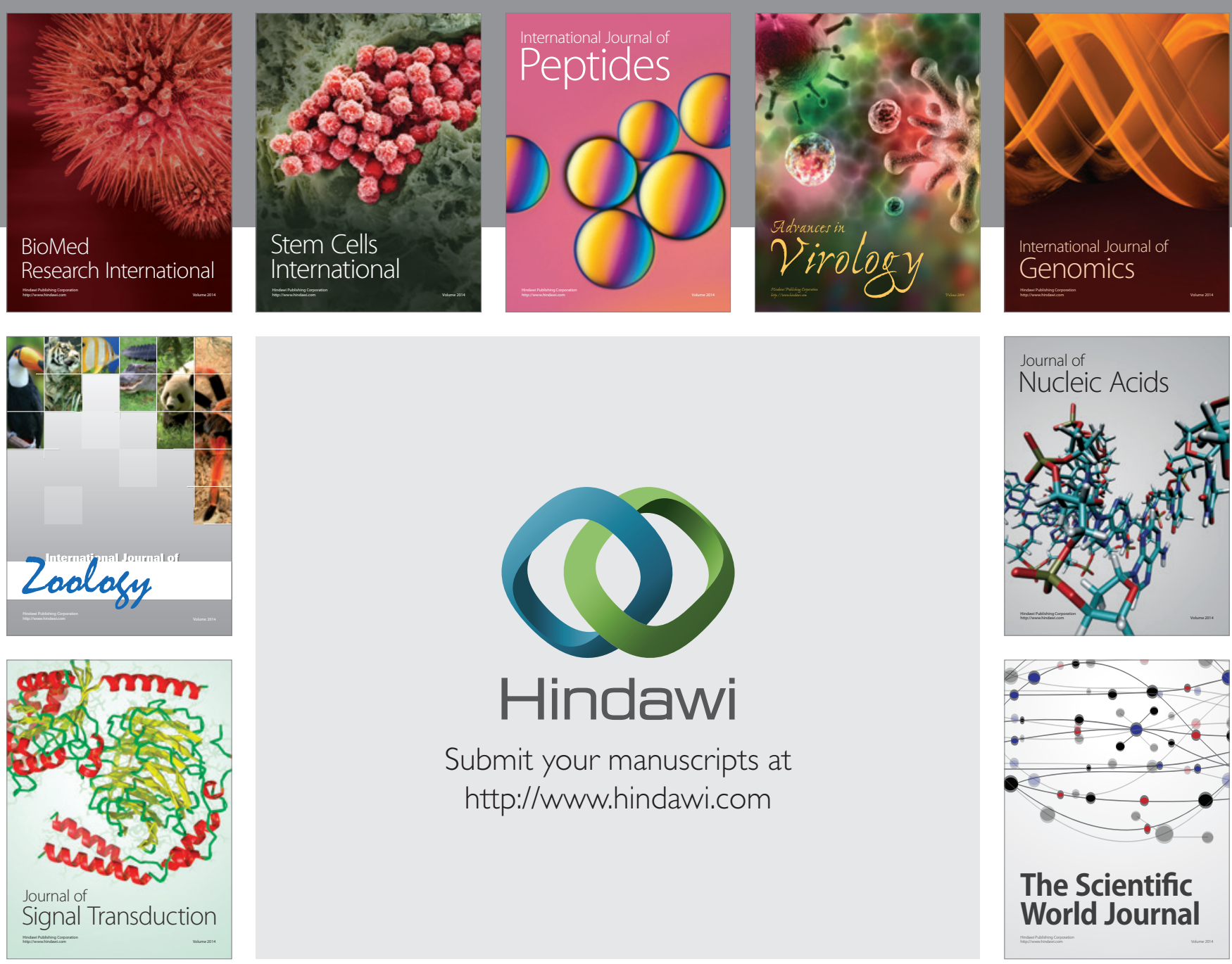

Submit your manuscripts at

http://www.hindawi.com
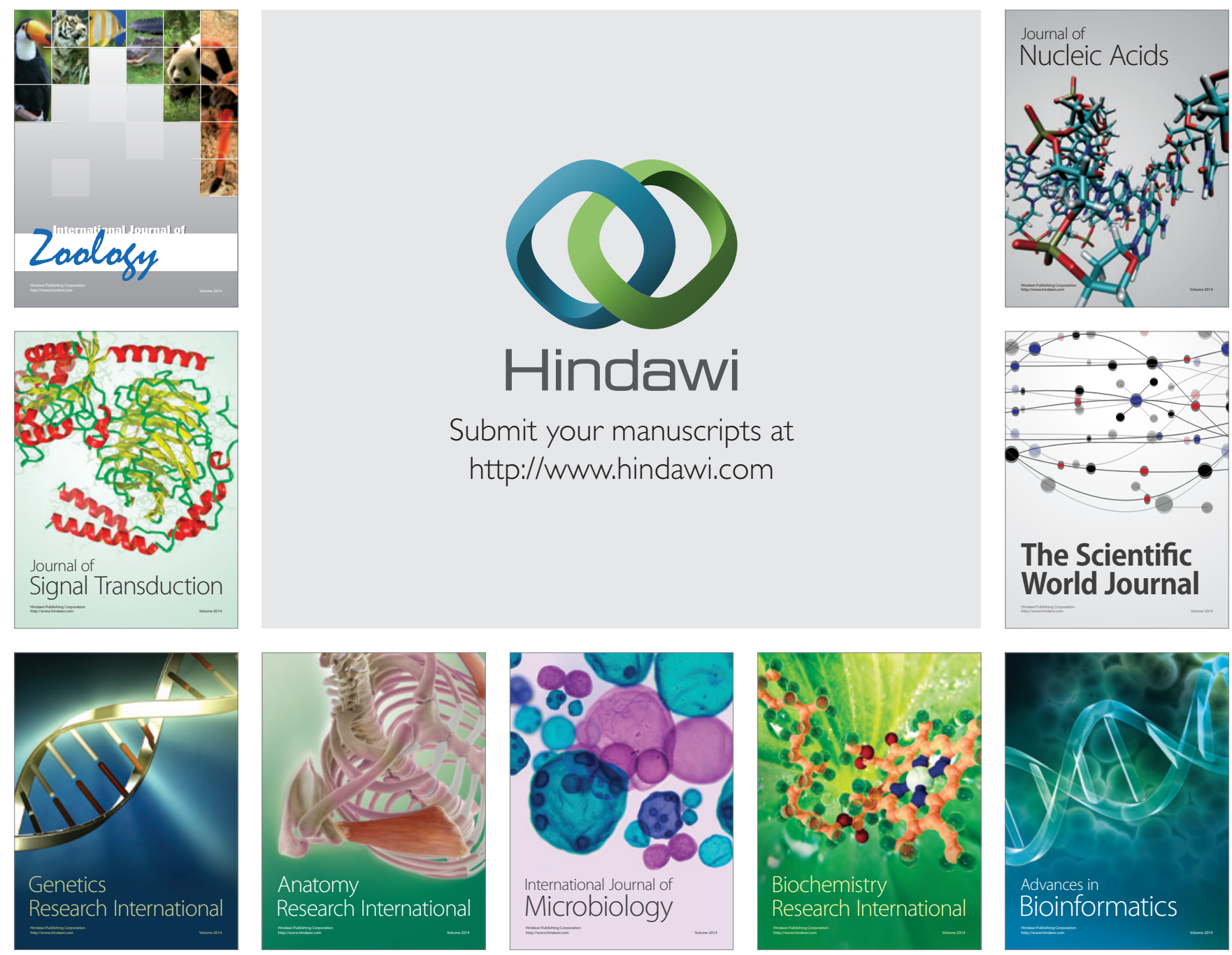

The Scientific World Journal
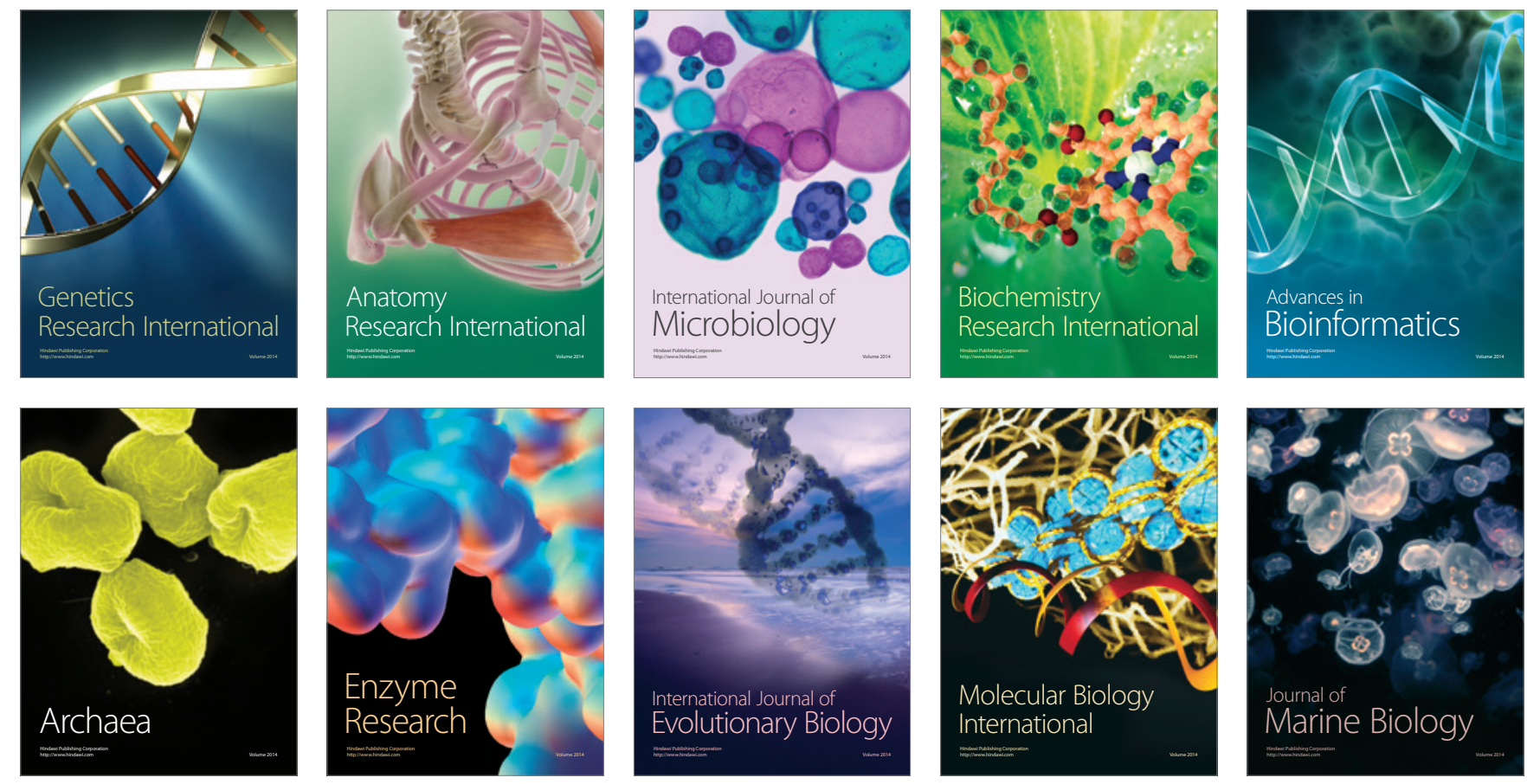